\title{
Impacts of the carbon emission trading system on China's carbon emission peak: a new data-driven approach
}

\author{
Liangpeng $\mathrm{Wu}^{1} \cdot$ Qingyuan $\mathrm{Zhu}^{2,3}$
}

Received: 7 March 2020 / Accepted: 9 December 2020 / Published online: 3 January 2021

(c) The Author(s), under exclusive licence to Springer Nature B.V. part of Springer Nature 2021

\begin{abstract}
Over the past four decades, China's extensive economic growth mode has led to substantial greenhouse gas emissions, and China has become the world's largest emitter since 2009. In order to alleviate the dual pressures from international climate negotiations and domestic environmental degradation, the Chinese government has pronounced it will reach its emission peak before 2030. However, through analyzing 12 scenarios, we found that it will be very difficult to meet this ambitious goal under the current widely used policies. With the trial implementation of China's carbon emission trading system (ETS), concerns arise over whether national ETS can accelerate the carbon peak process. In this paper, we propose a new proactive data envelopment analysis approach to investigate the impacts of national carbon ETS on carbon peak. Several important results are obtained. For example, we find that carbon ETS has a significant accelerating effect on carbon peak, which effect will advance the carbon peak by one to 2 years, and the corresponding peak values are reduced by $2.71-3$ Gt. In addition, the setting of carbon price in the current Chinese pilot carbon market is found to be overly conservative. Last, our estimation on the carbon trading volume indicates that the ETS lacks vitality as the annual average carbon trading volume only represents approximately $4.3 \%$ of the total average carbon emissions. Based on these findings, several policy implications are suggested regarding the means by which China can more smoothly peak its carbon emissions before 2030 and implement national carbon ETS.
\end{abstract}

Keywords Carbon emission trading system - Carbon peak - Proactive data envelopment analysis · Carbon marginal abatement cost

Qingyuan Zhu

zqyustc@mail.ustc.edu.cn

1 College of Management Engineering, Nanjing University of Information Science and Technology, Nanjing 210044, People's Republic of China

2 College of Economics and Management, Nanjing University of Aeronautics and Astronautics, Nanjing 211106, People's Republic of China

3 Research Center for Soft Energy Science, Nanjing University of Aeronautics and Astronautics, 29 Jiangjun Avenue, Nanjing 211106, China 


\section{Introduction}

Over the past four decades, economic growth has been a high priority issue for China, and its nominal gross domestic product (GDP) has grown approximately 220 times since 1978 (Zhang et al. 2017). However, such rapid growth is inextricably linked to the consumption of large amounts of energy, resulting in a high growth on greenhouse gas (GHG) emissions (Zhu et al. 2020a). In fact, China has surpassed the U.S. and become the largest $\mathrm{CO}_{2}$ emitter since 2009 (Wu et al. 2018). To alleviate the dual pressures from domestic environmental deterioration and international climate negotiations, China has announced its GHG emission targets in the "U.S.-China Joint Announcement on Climate Change" released in 2014. The central element of the target intends to peak $\mathrm{CO}_{2}$ emissions by 2030 or earlier. The carbon emission peak in China would have a significant impact on achieving the goal set in the Paris Agreement, which stipulated that the global average temperature rise should be controlled within $2{ }^{\circ} \mathrm{C}$ in this century. According to the fifth assessment report of intergovernmental panel on climate change's (IPCC), it would be possible to achieve the $2{ }^{\circ} \mathrm{C}$ target if global GHG emissions are reduced to 30-50 Gt carbon dioxide equivalent by 2030 (Mi et al. 2017), and China should maintain its maximum carbon emissions within $12 \mathrm{Gt}$ to better help the world achieve the $2{ }^{\circ} \mathrm{C}$ target. However, it is predicted that China's carbon dioxide emissions will grow to $18 \mathrm{Gt}$ by 2030 if China does not take measures to control GHG emissions (Tol 2013); in this scenario, the $2{ }^{\circ} \mathrm{C}$ target is unlikely to be achieved. Therefore, China inevitably needs to take measures to control its carbon emissions.

According to Kaya identity, there are three main strategies to reduce carbon emissions at the macro level: the economic scale, the technology and the structure effects (Kawase et al. 2006). Hence, previous studies on carbon reduction mainly focused on predicting changes based on these three strategies to investigate when China will achieve its carbon emission peak. Details are summarized in Table 1. For instance, Mi et al. (2017) assessed the trade-off between carbon reduction and economic growth using an input-output-based optimization method. They found China may achieve its peak before 2026 if the GDP growth rate is approximately 5\% over the next two decades. den Elzen et al. (2016) utilized bottom-up and FAIR/TIMER model to predict the time and the peak value of China's carbon peak. In their study, the projected peak time is 2030, and the corresponding carbon emission value ranges from 11.3 to $11.8 \mathrm{Gt}$. Studies on China's carbon peak with respect to different sectors and industries (such as power sector, industrial sector and non-ferrous metals industry) can also be found (Khanna et al. 2016; Li et al. 2018; Tang et al. 2018; Yu et al. 2018a). Although there are variations in the methods employed by abovementioned studies, one common finding can be obtained, i.e., China can realize its peak target before 2030. However, certain studies hold the opposite view that China cannot achieve carbon peak before 2030. For example, Meng et al. (2017) forecasted carbon emissions with respect to five scenarios to demonstrate that China cannot easily peak carbon emissions before 2030. According to Niu et al. (2016), China will peak carbon emissions in the year 2032 if China's GDP growth decelerates at an annual rate of 0.05\%. Yuan et al. (2014) set 13 scenarios according to Kaya identity to simulate China's energy and emission peak. They all obtained that China is less likely to peak before 2030, and the predicted peak time ranges from 2030-2035.

Although strategic policies have also incorporated different methods to predict the peak time and value, certain decisive policies [such as carbon emission trading system (ETS)] continue to be missed, since China's policies on energy and climate are developed and updated excessively fast. In December of 2017, the overall design of the national carbon 


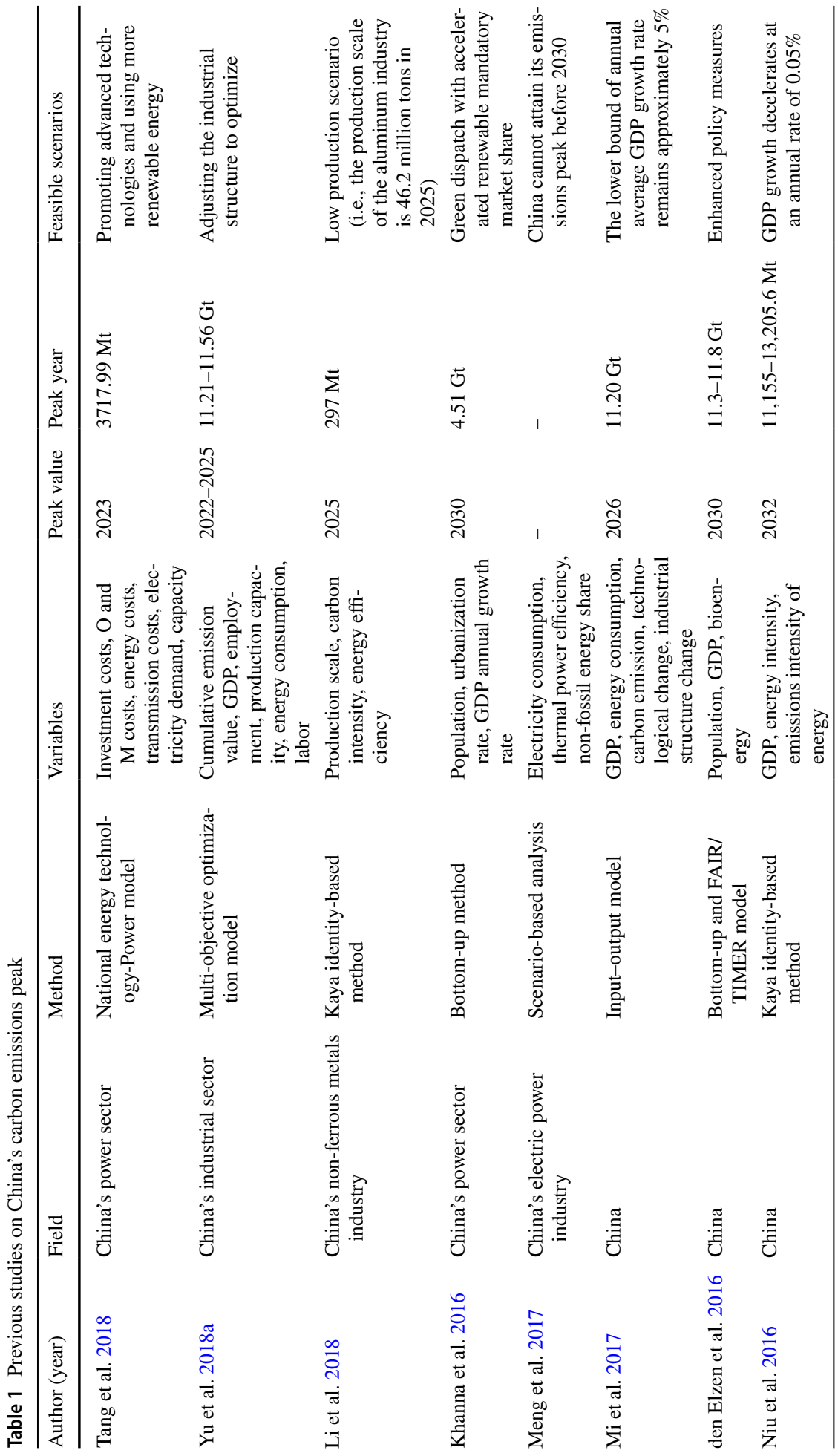




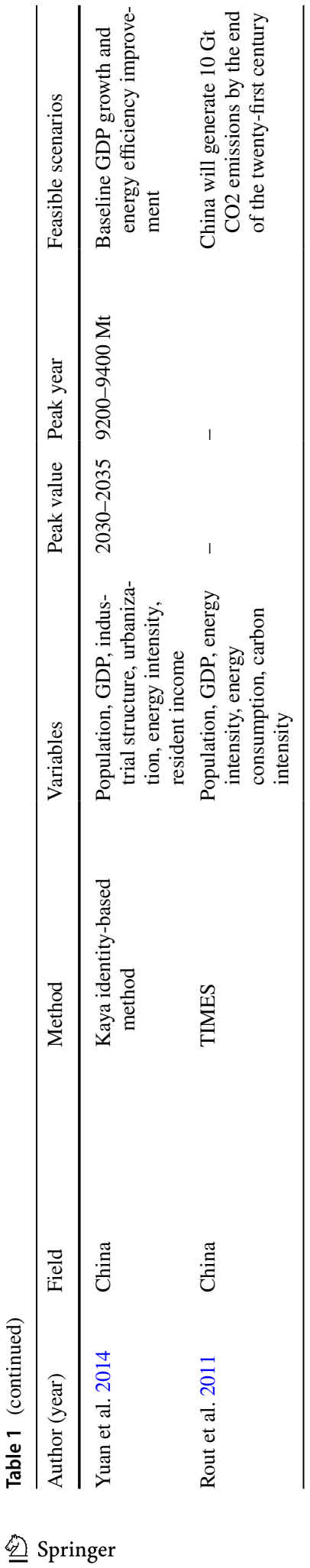


ETS for power industry has been completed and officially launched. The Chinese government also planned to establish the nationwide carbon trading market with respect to entire industries around 2020. That is, carbon trading market policy is bound to be implemented in China. Therefore, the impacts of carbon ETS on carbon emissions need to be further investigated.

There is extensive literature on carbon ETS, and the number of studies has been growing over years (details are shown in Table 2). Simulation-based methods are most widely used to investigate the impacts of carbon ETS on economy and environment (e.g., Hübler et al. 2014; Li and Jia 2016; Liu et al. 2016, 2017; Tang et al. 2015; Wang et al. 2015; Zhu et al. 2017). In these studies, the carbon reduction target is normally treated as an exogenous variable such that they can determine how many GDP losses by reducing carbon emissions. It is demonstrated that GDP losses can be considerably retrieved through implementing carbon ETS. However, uncertainties could be expanded by simulation-based methods since the results are highly dependent on the choice of models and assumptions in models. Furthermore, the procedure of collecting data is complicated; even some data cannot be accurately found from official reports. To avoid these uncertainties, operational optimization methods are proposed (Li et al. 2017; Song et al. 2018).

Among operational optimization methods, the data envelopment analysis (DEA) method is much appreciated by scholars due to its features, which are accurate, flexible in data requirements and can simulate the production process (Zhou et al. 2015). For example, Färe et al. $(2014,2013)$ proposed the DEA-based method to estimate the potential economic gains from a spatial tradable permit scheme and a spatial-temporal tradable permit scheme in U.S. electric power plants. The results indicated that the rigidity of the pollutant permits trading mechanism will be the barrier to attaining pollution cost savings. Wang et al. (2016a) applied the same method to estimate the potential gains from China's carbon ETS. The researchers found approximately $46 \%$ and $26 \%$ of the cost saving could be realized when the carbon permits are allowed to be traded spatially and temporally, respectively. Similar empirical studies with respect to China's thermal power industry and industrial sector can also be found (e.g., Wang et al. 2016b; Yu et al. 2018b).

Reviewing above studies on carbon emission peak and carbon ETS, several flaws are summarized as follows: First, the issue that combines carbon peak with carbon ETS has rarely been studied. However, this issue is of great importance for policymakers because the results can remind them whether they need to adjust current policies or not. Second, the underlying assumption in existing methods would cause huge impacts on economy. Specifically, considering China as a developing country, economic development remains China's primary task, most existing literatures' research paradigm is maximize economic growth subject to the given emission reduction targets. However, the imprecise pre-set emission reduction targets might have already caused great damage to the economy. Hence, the assumption of minimizing carbon emissions as much as possible without damaging economic development will be more appropriate. Third, when the DEA method is applied to measure the impacts of carbon ETS on China's economy and environment, the unsmooth characteristic of the DEA production frontier is not taken into account, namely that the marginal production (MP) of certain units is not unique.

To fill these gaps, this paper combines Kaya identity and a new proactive DEA-based method to analyze whether the carbon ETS will accelerate China's carbon peaking process. If so, how many years ahead of schedule will China reach its peak, and how much will the corresponding carbon emissions be? Specifically, different scenarios are set based on Kaya components to predict the carbon emissions peak given that carbon permits are not allowed to be traded. Then, a proactive DEA-based method based on a nonlinear 0-1 programming 


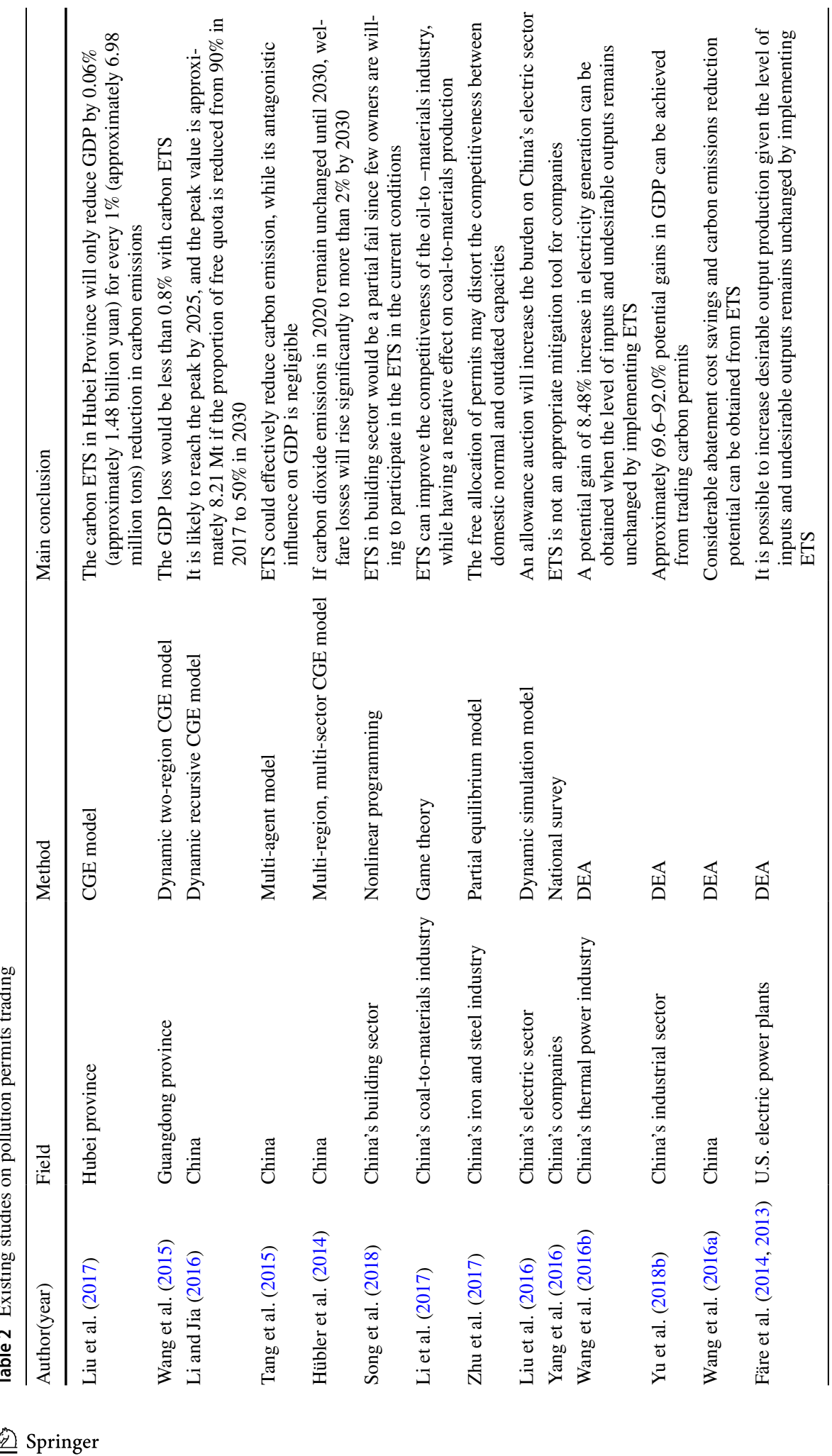


is proposed to evaluate the potential impacts of the national carbon trading policy on China's carbon emissions. Finally, the eventual peak time and value are adjusted when carbon emissions permits are tradeable.

The main theoretical contributions of this paper are summarized as follows: (1) this study provides the first attempt to consider the carbon trading policy to predict the likelihood that China will peak its emissions by 2030 through utilizing the new proactive DEAbased method rather than complex simulation-based methods. (2) The optimal energy input and carbon emissions of each province can be adjusted using a proactive DEA-based method given that the carbon trading policy cannot negatively affect GDP. Additionally, suppliers and demanders of carbon emissions permits can be identified. (3) Results of this paper may elucidate the wisdom of the government's decision and even potentially cause a change in current policy (namely the results from this paper can provide the reference for policymakers that which current scenarios can be adopted to achieve the carbon peak target when the carbon trading policy is considered).

The remainder of this paper is organized as follows: Section 2 introduces the methodology. Section 3 shows the empirical study and unveils the corresponding results. The conclusions and policy implications are given in Sect. 4.

\section{Methodology}

\subsection{Carbon peak forecasting without carbon ETS}

As an analytical framework for studying the change characteristics of things, decomposition analysis methods have been applied more and more in environmental economic research. There are two common decomposition methods, one is index decomposition analysis (IDA), and the other is structural decomposition analysis (SDA). Compared with SDA method which needs input-output table data as support, IDA method only needs department aggregate data and is more widely used. Kaya identity (Kaya and Yokobori 1997), as a typical IDA decomposition method, is the mainstream analysis method to explore the driving factors of carbon emissions at present. Kaya identity states that total emission level can be expressed as the product of different inputs, so it has the advantages of simple mathematical form, no residual decomposition and strong explanation for the driving factors of carbon emission change. According to the Kaya identity, the macro-carbon emissions from energy consumption can be expressed as:

$$
\mathrm{CO}_{2}=\frac{\mathrm{CO}_{2}}{\text { Energy }} * \frac{\text { Energy }}{G D P} * G D P
$$

Based on the identity, $\mathrm{CO}_{2}$ is decomposed into three variables: carbon emission intensity, energy intensity and GDP. (1) carbon emission intensity (CI), emissions from one unit of energy consumption, reflects the energy consumption structure of a country or region. The gradual adjustment of a coal-oriented energy structure to a clean and renewable-oriented energy structure will effectively reduce carbon intensity. (2) energy intensity (EI), energy consumption per unit GDP, is one of the most commonly used indicators of the comprehensive energy use efficiency of a country or region, which reflects the economic benefits of energy utilization. The lower the energy intensity is, the higher the energy use technology will be. (3) GDP represents the economic scale of a country or region; its growth cannot be separated from the use of energy, thus increasing carbon emissions. For 
developing countries, GDP growth is rigid and is the most essential driving factor for the growth of various emissions.

Considering that CI and EI have shown a decreasing trend, whereas GDP has shown an increasing trend, China can reach its peak only when the emission reduction value caused by decreasing CI and EI are greater than the emission increase value caused by expanding GDP. Specifically, as the energy structure is upgraded and the energy use is improved, the emission reduction effects will be equal to the emission increase effect of economic growth, and China's emissions' curve will attain an inflection point (i.e., peak point). Thereafter, China's carbon emission shows a declining trend. It should be noted that both emission reduction and increase effects are affected by the current corresponding policies. Hence, the occurrence year of China's carbon emissions peak and its peak value are forecasted based on the combinations of the change trends of three variables with respect to different scenarios. The change trends of the CI and EI are forecasted by utilizing a unitary regression mode, and the GDP increase trend is forecasted by the compound growth model (detailed forecasted results are available in Sect. 3.2).

\subsection{Carbon peak forecasting with carbon ETS}

Decomposition analysis methods are wildly used to study the change characteristics of pollution emissions, including SDA, Arithmetic mean Divisia Index (AMDI), Logarithmetic mean Divisia Index (LMDI), etc. Although these methods, which focus on exploring the contribution of various driving factors to the emission changes, play the important role in explaining the causes of pollution emission changes, they are powerless to explain the influence of policies (such as carbon ETS) on pollution emissions. To reduce bias caused by choosing evaluated methods, this paper employs the DEA-based method, since this method is accurate, flexible in data requirements and can simulate the production process. More importantly, by constructing corresponding carbon trading constraints in the model, DEA-based method can further evaluate the carbon reduction effect of carbon ETS (Wu and Gong 2020).

In contrast to the existing DEA-based methods, this paper proposes a new proactive DEA evaluation method in which two features are considered to make our method more realistic. (1) Each province tries its best to reduce carbon emissions without damaging economic development rather than each province potentially maximizing its GDP under the given carbon emissions reduction target. The assumption is set based on two realistic reasons: on the one hand, that emission reduction at the expense of economic development may not be suitable for China's current development strategy, and on the other hand, that it is difficult to set precise emission reduction targets for each province. (2) The reduction of carbon emissions is mainly due to the reduction of energy input, and the energy adjustment of a province is based on its energy MP. With these two features, each province could adjust its energy input proactively according to its energy MP and economic development status, and provinces that intend to increase energy could purchase carbon emission permits from provinces that intend to reduce energy input, thus realizing the circulation and trading of carbon emission permits.

\subsubsection{The estimation of MP}

First, the energy marginal product rate needs to be evaluated. In this study, there are three inputs $(e, c$ and $l)$ of energy, capital stock and labor force, one desirable output $(y)$ of GDP for 
each $j=1,2, \cdots, n$ province, and $\lambda_{j}$ is the multiplier of $j$ th province. The production possibility set under variable-return-to-scale (VRS) is defined as (Zhu et al. 2019, 2020b):

$$
\begin{gathered}
T=\left\{(e, c, l, y) \mid \sum_{j=1}^{n} \lambda_{j} e_{j} \leq e, \sum_{j=1}^{n} \lambda_{j} c_{j} \leq c, \sum_{j=1}^{n} \lambda_{j} l_{j} \leq l,\right. \\
\left.\sum_{j=1}^{n} \lambda_{j} y_{j} \geq y, \sum_{j=1}^{n} \lambda_{j}=1, \lambda_{j} \geq 0, \forall j\right\}
\end{gathered}
$$

From model (2), the production possibility set is estimated by a piece-wise linear concave function that envelops all observations. Thus, in contrast to other production function estimation methods (such as Stochastic Frontier Analysis, SFA), the production frontier estimated by DEA is not smooth everywhere. In other words, certain DEA's observations on the production frontier do not have unique MPs. Figure 1 shows the MPs and production frontiers with one input and one output estimated by SFA and DEA, respectively.

From Fig. 1, the MP of each observation on the SFA production frontier is unique, whereas several observations' (such as point $j$ ) MPs estimated by DEA are not unique. Given the nonunique MP situation, this paper employs the directional derivative technique (Podinovski and Førsund 2010) to calculate the left side marginal production (left-MP) and the right side marginal production (right-MP).

Let $v_{\mathrm{er}}, v_{\mathrm{cr}}, v_{\mathrm{lr}}, u_{r}$ and $u_{0 r}$ be the shadow prices of energy, capital stock, labor force, GDP and intercept term of $r$ th province, respectively. Then, $r$ th province's energy right-MP, which represents consumed GDP expanding with an increase in energy consumption, can be calculated by the following model.

$$
\begin{aligned}
& \text { Right }-\operatorname{MP}(r)=\beta_{r}^{+}=\min v_{e r} \\
& \text { s.t. } v_{\mathrm{er}} e_{r}+v_{\mathrm{cr}} c_{r}+v_{\mathrm{lr}} l_{r}-u_{r} y_{r}+u_{\mathrm{or}}=0 ; \\
& \quad v_{\mathrm{er}} e_{j}+v_{\mathrm{cr}} c_{j}+v_{l r} l_{j}-u_{r} y_{j}+u_{\mathrm{or}} \geq 0, \forall j \text { and } j \neq r ; \\
& \quad v_{\mathrm{er}}, v_{\mathrm{cr}}, v_{\mathrm{lr}} \geq 0, u_{\mathrm{or}} \text { free. } \\
& \quad u_{r}=1
\end{aligned}
$$

To calculate the energy left-MP, which represents consumed GDP contracting with a decline in energy consumption, the objective function of model (3) is replaced by the following function.

$$
\text { Left }-\mathrm{MP}(r)=\beta_{r}^{-}=\max v_{\mathrm{er}}
$$

According to the proof of Podinovski and Førsund (2010), the right-MP always exists. The left-MP exists when the energy consumption level of $r$ th province can be reduced; otherwise, model (4) is an unbounded objective function. It should be noted that only the provinces on the production frontier can be defined through the above two models, and MPs for inefficient provinces are defined according to the assumption that inefficient provinces' MPs are the same as the MPs of their reference provinces on the production frontier (Lee and Johnson 2014). 
Fig. 1 Marginal production rate estimation

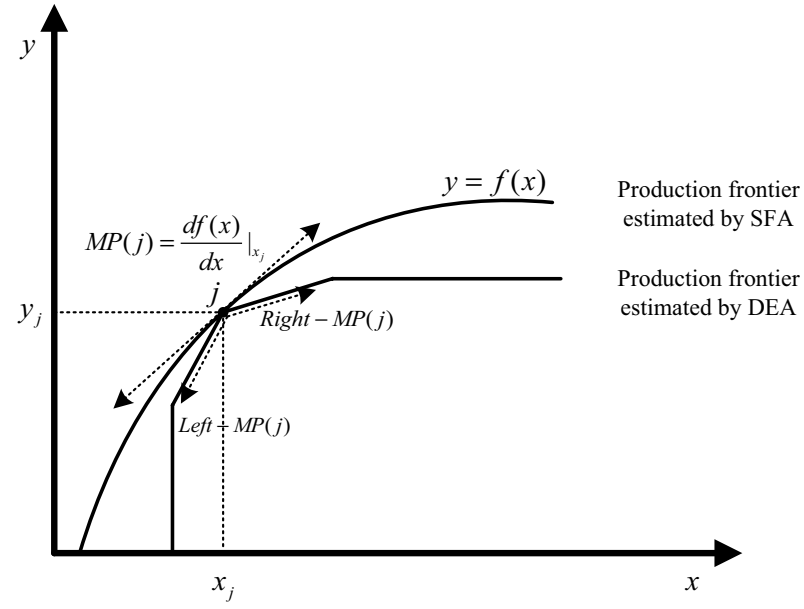

\subsubsection{The estimation of the impact of carbon ETS on carbon emissions}

Let $\beta_{r}^{+}, \beta_{r}^{-}, \theta$ and $d_{r}$ be the right-MP, the left-MP, the energy reduction effect of carbon ETS and the additional energy adjustment, respectively. The total energy consumption (TEC) of the province is composed of the energy reduction effect of carbon ETS and an additional energy adjustment caused by trading permits; it can be further expressed as:

$$
\mathrm{TEC}_{r}=\theta * e_{r}+d_{r}
$$

From model (5), the eventual total energy adjustment (TEA) is defined as:

$$
\mathrm{TEA}_{r}=\mathrm{TEC}-e_{r}
$$

If the value of TEA is positive, this represents that the province intends to expand its energy input to increase GDP; according to definition of MP, the adjusted GDP (AGDP) is measured as (Lee and Johnson 2014):

$$
\mathrm{AGDP}_{r}=\beta_{r}^{+} * \mathrm{TEA}+y_{r}
$$

Otherwise, the province is likely to contract its energy consumption; the AGDP is measured as:

$$
\mathrm{AGDP}_{r}=\beta_{r}^{-} * \mathrm{TEA}+y_{r}
$$

Then, under the carbon ETS, the inputs and output of the $r$ th province are adjusted from $\left(e_{r}, c_{r}, l_{r}, y_{r}\right)$ to $\left(\mathrm{TEC}_{r}, c_{r}, l_{r}, \mathrm{AGDP}_{r}\right)$. Note that the adjustments of inputs and output are not arbitrary but are based on corresponding adjustment constraints. Since the assumption underlying the model is reducing emissions without damaging economic development, the first constraint, the national total GDP, should be greater than the original national total GDP:

$$
\sum_{r=1}^{n} \mathrm{AGDP}_{r} \geq \sum_{r=1}^{n} y_{r}
$$


To make the carbon trading market Pareto efficient, it is assumed that the carbon trading market is clean. In other words, the second constraint is there are no idle carbon emission permits and no excess demand in the market:

$$
\sum_{r=1}^{n} \mathrm{CI} * d_{r}=0
$$

Since the value of CI is positive, Eq. (10) can be rewritten as:

$$
\sum_{r=1}^{n} d_{r}=0
$$

Additionally, carbon ETS may promote production technology; however, this promotion is not significant in the short term. That is, the production frontier under carbon ETS will not be extrapolated. Hence, the third constraint is expressed as all adjusted observations remain enveloped by the original production frontier:

$$
\left(\mathrm{TEC}_{r}, c_{r}, l_{r}, \mathrm{AGDP}_{r}\right) \in T
$$

The objective function is to use the given energy input to minimize carbon dioxide emissions. In sum, the impact of carbon ETS on carbon emissions can be assessed by using the following proactive DEA-based method:

$$
\begin{aligned}
& \min \theta \\
& \text { s.t. }\left(T E C_{r}, c_{r}, l_{r}, A G D P_{r}\right) \in T, \forall r ; \\
& \quad \sum_{r=1}^{n} A G D P_{r} \geq \sum_{r=1}^{n} y_{r} ; \\
& \quad \sum_{r=1}^{n} d_{r}=0 ; \\
& \quad T E C_{r}, c_{r}, l_{r}, A G D P \geq 0 ;
\end{aligned}
$$

It should be noted that model (13) cannot be solved because the logical statement (i.e., if $\mathrm{TEA}_{r} \geq 0$, then $\mathrm{AGDP}_{r}=\beta_{r}^{+} * \mathrm{TEA}+y_{r}$; otherwise, $\mathrm{AGDP}_{r}=\beta_{r}^{-} * \mathrm{TEA}+y_{r}$ ) is included in the model. Hence, the $0-1$ binary variable is employed to convert the logical statement to a mathematical expression. The detailed mathematical expression is as follows:

$$
\begin{aligned}
& \beta_{r}=\beta_{r}^{+} * z_{r}+\beta_{r}^{-} *\left(1-z_{r}\right) \\
& \mathrm{TEA}_{r} \leq M * z_{r} \\
& \mathrm{TEA}_{r} \geq-M *\left(1-z_{r}\right) \\
& z_{r} \in\{0,1\}
\end{aligned}
$$

where $M$ is a sufficiently positive number. Based on the conversion, the model (13) can be rewritten as: 


$$
\begin{aligned}
\min \theta & \\
\text { s.t. } & \sum_{j=1}^{n} e_{j} * \lambda_{j r} \leq \theta * e_{r}+d_{r}, \quad r=1,2, \ldots n ; \\
& \sum_{j=1}^{n} c_{j} * \lambda_{j r} \leq c_{r}, \quad r=1,2, \ldots n ; \\
& \sum_{j=1}^{n} l_{j} * \lambda_{j r} \leq l_{r}, \quad r=1,2, \ldots n ; \\
& \sum_{j=1}^{n} y_{j} * \lambda_{j r} \geq y_{r}+\left(\theta * e_{r}+d_{r}-e_{r}\right) * \beta_{r}, \quad r=1,2, \ldots n ; \\
& \sum_{j=1}^{n} \lambda_{j r}=1, \quad r=1,2, \ldots n ; \\
& \beta_{r}=\beta_{r}^{+} * z_{r}+\beta_{r}^{-} *\left(1-z_{r}\right), \quad r=1,2, \ldots n ; \\
& \theta * e_{r}+d_{r}-e_{r} \leq M * z_{r}, \quad r=1,2, \ldots n ; \\
& \theta * e_{r}+d_{r}-e_{r} \geq-M *\left(1-z_{r}\right), \quad r=1,2, \ldots n ; \\
& z_{r} \in\{0,1\}, \quad r=1,2, \ldots n ; \\
& \sum_{r=1}^{n}\left(\theta * e_{r}+d_{r}-e_{r}\right) * \beta_{r} \geq 0 ; \\
& \sum_{r=1}^{n} d_{r}=0 ; \\
\forall j, r, \lambda_{j r} \geq 0 &
\end{aligned}
$$

Model (15) is a non-linear $0-1$ programming with $(n+1)^{2}$ variables and $9 n+2$ constraints, and the software called the "general algebraic modeling system (GAMs)" is employed to solve model (15).

Finally, the total carbon emissions reduction $\left(\mathrm{TRCO}_{2}\right)$ caused by carbon ETS is measured as:

$$
\mathrm{TRCO}_{2}=C I *(1-\theta) * \sum_{r=1}^{n} e_{r}
$$

\subsubsection{The accelerating effect estimation of carbon ETS on the carbon peak}

It is assumed that the carbon emissions in the year of $t$ without carbon ETS are measured by using the three predicted variables, i.e., $\mathrm{CI}_{t}, \mathrm{EI}_{t}$ and $\mathrm{GDP}_{t}$ (Li et al. 2018).

$$
C O_{2 t}=G D P_{t} * C I_{t} * E I_{t}
$$

In addition, the carbon reduction is forecasted and is denoted by $\mathrm{TRCO}_{2 t}$. Then, the final carbon emissions under carbon ETS is evaluated as:

$$
\mathrm{FCO}_{2 t}=\mathrm{CO}_{2 t}-\mathrm{TRCO}_{2 t}
$$


There are three means to predict the trajectory of $\mathrm{TRCO}_{2 t}$. The first one is to predict the relationship between $\mathrm{TRCO}_{2 t}$ and time $t$ directly. The second mean is the change tendency in $\theta$ is projected, and the $\mathrm{TRCO}_{2 t}$ is expressed as the product of $\mathrm{CI}_{t},\left(1-\theta_{t}\right)$ and $\sum_{r=1}^{n} e_{\mathrm{rt}}$. The result from this method is most persuasive since linkages between $\mathrm{TRCO}_{2 t}$ and policy scenarios (changes in $\mathrm{CI}_{t}$ and $\sum_{r=1}^{n} e_{\mathrm{rt}}$ are affected by policy scenarios) can be displayed. However, there may be no statistical significance in the prediction of $\theta$ if the trajectory of $\theta$ fluctuates excessively. The last method is predicting the change trend of hidden factors, which affect the $\mathrm{TRCO}_{2 t}$ significantly, and the trajectory of $\mathrm{TRCO}_{2 t}$ is projected indirectly.

\section{Empirical analysis}

\subsection{Data description}

In contrast to the current pilot carbon emission trading market at lower levels, the trading participants in the nationwide carbon ETS are provinces; hence, the macroeconomic data of China's 29 provinces from 2001 to 2016 (except Taiwan, Tibet, Macau, and Hong Kong; moreover, Chongqing and Sichuan are merged into one province to maintain data consistency) has been collected. The particular collection techniques for the five variables are as follows:

(1) The perpetual inventory method is used to calculate the capital stock (100 million yuan):

$$
c_{T}=c_{T-1}\left(1-\delta_{T}\right)+I_{T},
$$

where $c_{T}$ denotes the total capital stock in year $T ; \delta_{T}$ is the assets depreciation rate, and we set the depreciation rate at $9.6 \%$ according to Zhang et al. (2004); $I_{T}$ denotes the newly increased capital stock. It should be noted that the primary capital stock is proposed by Zhang et al. (2004), and we further expand their results to 2016. The capital stocks in different years are converted into 2000 prices.

(2) Labor force (10,000 people): the people engaged at the end of the year represent the labor, and the date is clearly reported in provincial Statistic Yearbook.

(3) The following formula is utilized to measure the energy consumption (10,000 tons of standard coal):

$$
E_{T}=\sum_{i} E_{i T} \rho_{i}
$$

where $E_{i T}$ indicates the type of energy usage, including crude oil, gasoline, fuel oil, coal, natural gas, coke and diesel oil; $\rho_{i}$ denotes the conversion coefficient of standard coal for $i$ th energy.

(4) GDP (100 million yuan) deflates to the constant 2000 price.

(5) The carbon dioxide emissions are estimated on the basis of the Intergovernmental Panel on Climate Change (IPCC, 2006), and the specific formula is:

$$
\mathrm{CO}_{2}=\sum_{i} E_{i} * N C V_{i} * C E F_{i} * C O F_{i} * \frac{44}{12},
$$


where $E_{i}, N C V_{i}, C E F_{i}$ and $C O F_{i}$ are the energy consumption, net calorific value, carbon emission coefficient and carbon oxidation factor of $i$ th energy, respectively. The $44 / 12$ is a coefficient converting carbon into $\mathrm{CO}_{2}$.

The descriptive statistics for inputs and outputs for China are presented in Table 3.

\subsection{Results and discussion}

\subsubsection{Trajectory of GDP}

Since the reform and opening up, China's economy has developed rapidly, with an average annual growth rate of $9.7 \%$, which is 2.5 times the global growth rate. In addition, as of 2010, China has become the world's second-largest economy with 27,346.43 billion 2000 yuan GDP (Fig. 2).

To turn the economic development mode towards quality-efficiency, China has slowed its economic growth rate and entered the "new normal" in 2013. Hence, the future GDP is predicted by the composite growth model; it can be expressed as:

$$
\mathrm{GDP}_{t}=\mathrm{GDP}_{t-1} *\left(1+r_{0}-r_{1}(t-2016)\right),
$$

where $r_{0}$ is the GDP growth rate in 2016, and $r_{1}$ is the GDP deceleration rates. In this paper, the deceleration rates are set at $0.05 \%, 0.1 \%$ and $0.15 \%$, respectively, which mean GDP growth will slow at $0.05 \%, 0.1 \%$ and $0.15 \%$ per respective year. Additionally, based on the predicted results from national and international studies (i.e., the annual economic growth rate under the "new normal" will stabilize between 5 and 8\%) (Niu et al. 2016), $r_{0}-r_{1}(t-2016)$ is set at a constant $6.5 \%$. There is no significant difference in the prediction results before 2026, and the results predicted under $r_{1}=0.05 \%$, and the growth rate is $6.5 \%$ also showed no significant difference. Different predicted GDPs with respect to four growth rates are shown in Fig. 3.

\subsubsection{Trajectory of $\mathrm{Cl}$}

CI, emissions from one unit of energy consumption, reflects the cleanliness of energy consumption. As the proportion of clean energy has gradually increased from $6.67 \%$ in 2005 to $9.6 \%$ in 2013 and to $10.4 \%$ in 2016 , CI showed a steady downward trend, declining from 2.02 in 2005 to 1.98 to 2016. The detailed change trend of CI is shown in Fig. 4. From Fig. 4, there is a strong linear relationship between time and CI after 2005, and the linear function can be expressed as:

$$
\mathrm{CI}_{t}=-0.0037 * t+9.4572\left(R^{2}=0.9882\right)
$$

\subsubsection{Trajectory of El}

EI, reflecting comprehensive energy use efficiency of a country or region, has shown a fluctuating decline in the improvement of energy use efficiency (see in Fig. 5). In terms of 
Table 3 Summary Statistics for Inputs and Outputs in China, 2001-2016

\begin{tabular}{llllll}
\hline Statistics & $\begin{array}{l}\text { Capital stock } \\
(100 \text { million yuan })\end{array}$ & $\begin{array}{l}\text { Labor force } \\
(10,000 \text { people })\end{array}$ & $\begin{array}{l}\text { Energy con- } \\
\text { sumption } \\
(10,000 \text { tons of } \\
\text { standard coal })\end{array}$ & $\begin{array}{l}\text { GDP } \\
(100 \text { million yuan })\end{array}$ & $\begin{array}{l}\text { Carbon } \\
\text { dioxide } \\
\text { emissions } \\
(10,000 \text { tons })\end{array}$ \\
\hline Mean & $303,791.65$ & $74,980.87$ & $451,644.15$ & $278,468.38$ & $904,359.22$ \\
Median & $307,085.77$ & $74,939.37$ & $466,340.91$ & $251,937.82$ & $937,921.38$ \\
SD & $74,059.547$ & $5,691.15$ & $152,691.85$ & $140,636.20$ & $301,537.44$ \\
\hline
\end{tabular}

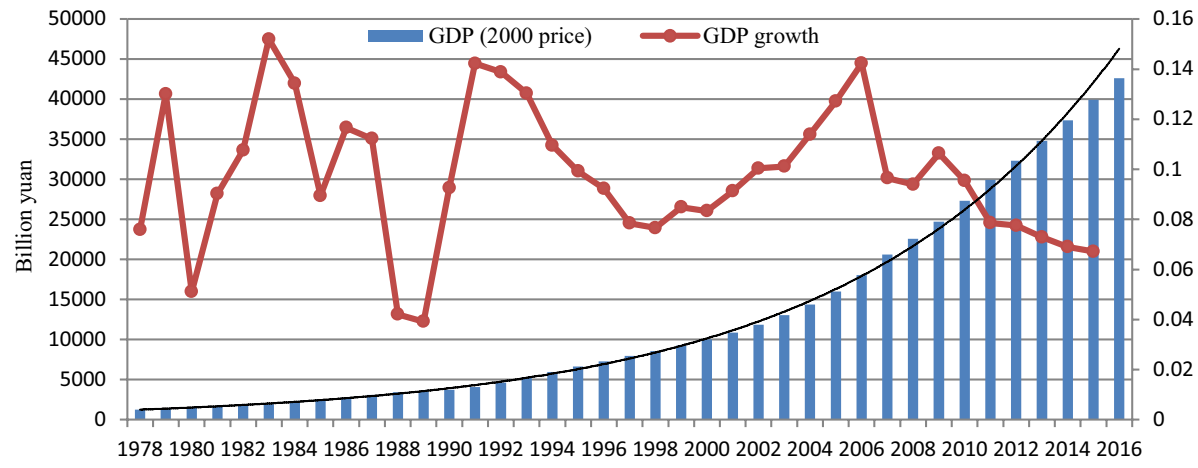

Fig. 2 China's GDP and GDP growth rate from 1978 to 2016

residual square sum and statistic distribution rule of error, there is a good fit between EI and the time exponent, and the predicted function can be expressed as:

$$
\mathrm{EI}_{t}=2.3164 * e^{-0.054(t-2004)}\left(R^{2}=0.9776\right)
$$

Considering the constraint effect of policy, i.e., Chinese government has announced that the carbon emissions per unit of GDP by 2030 should be reduced by $60-65 \%$ compared with the level in 2005 at the 2009 Copenhagen Summit, the corresponding EI should range from 0.780 to 0.891 Ton coal equivalent/10,000 yuan in 2030. Let the EI in 2030 be 0.780 and 0.891 Ton coal equivalent/10,000 yuan, respectively; the predicted functions can be expressed as:

$$
\begin{aligned}
& \mathrm{EI}_{t}=2.168 * e^{-0.042(t-2004)}\left(R^{2}=0.9632\right) \\
& \mathrm{EI}_{t}=2.107 * e^{-0.038(t-2004)}\left(R^{2}=0.9199\right)
\end{aligned}
$$

EI in 2030 predicted by Eq. (24) is 0.569 Ton coal equivalent / 10,000 yuan and is lower than the results measured from (25) and (26); hence, Eqs. (24)-(26) represent high, medium and low change rates of EI, respectively; detailed predicted results are shown in Fig. 5. From the figure, it is shown that it would be difficult for China to reduce its EI to the world average ( 0.125 per $\mathrm{kg}$ oil equivalent/2011 \$) before 2050 even if with a high change 


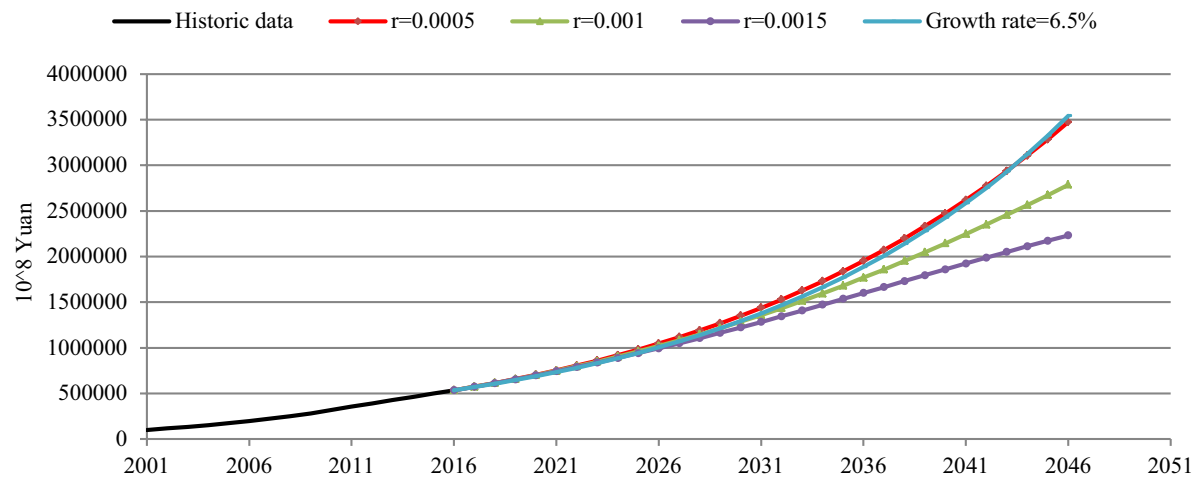

Fig. 3 Change trends in GDP

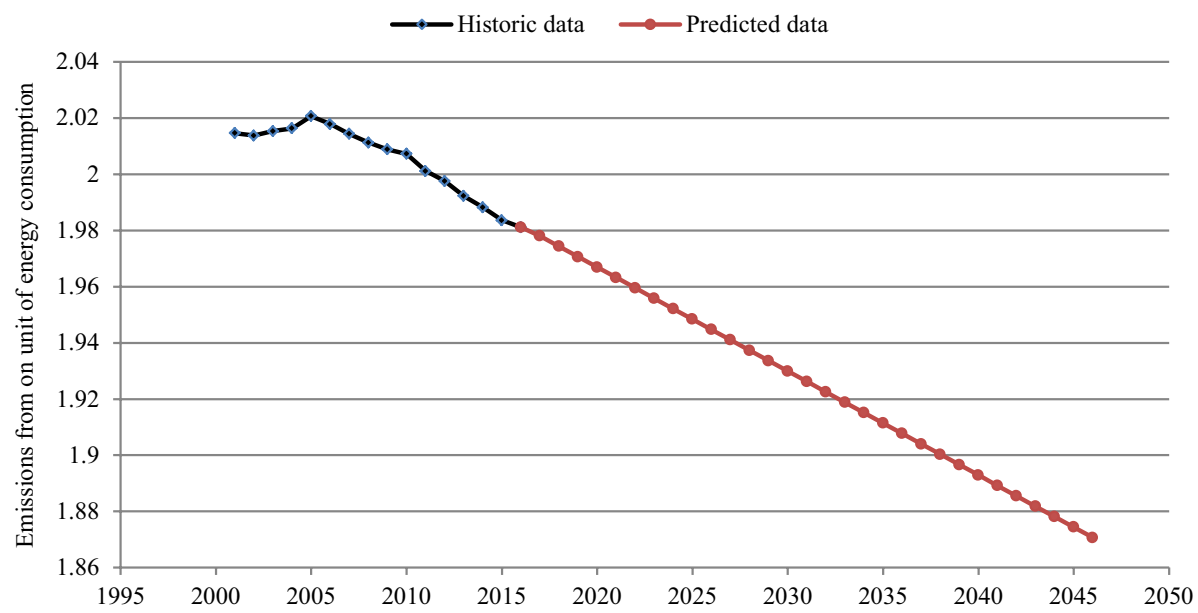

Fig. 4 Change trend in CI

rate. This finding indicates that China continues to have substantial potential for further decreasing its EI.

\subsubsection{Trajectory of carbon emissions under different scenarios}

As the largest $\mathrm{CO}_{2}$ emitter, China's emissions increased year over year. The fast-rising trend was most evident during 2000 and 2011. Carbon emissions increased from 42,192 billion tons in 2000 to 120,120 billion tons in 2011, an increase of approximately 2.85 times. Thereafter, carbon emissions have shown a slight growth trend (see Fig. 6). To forecast the change of Chinese carbon emissions, 12 scenarios have been simulated based on the change trends of the above three variables. The specific descriptions of the 12 scenarios are shown in Table 4, and the future carbon emissions with the 12 scenarios are shown in Fig. 6.

Among the 12 scenarios, Chinese carbon emission peaks occurs before 2045 in 6 scenarios, and China can realize its target before 2030 in only two scenarios. Specifically, 


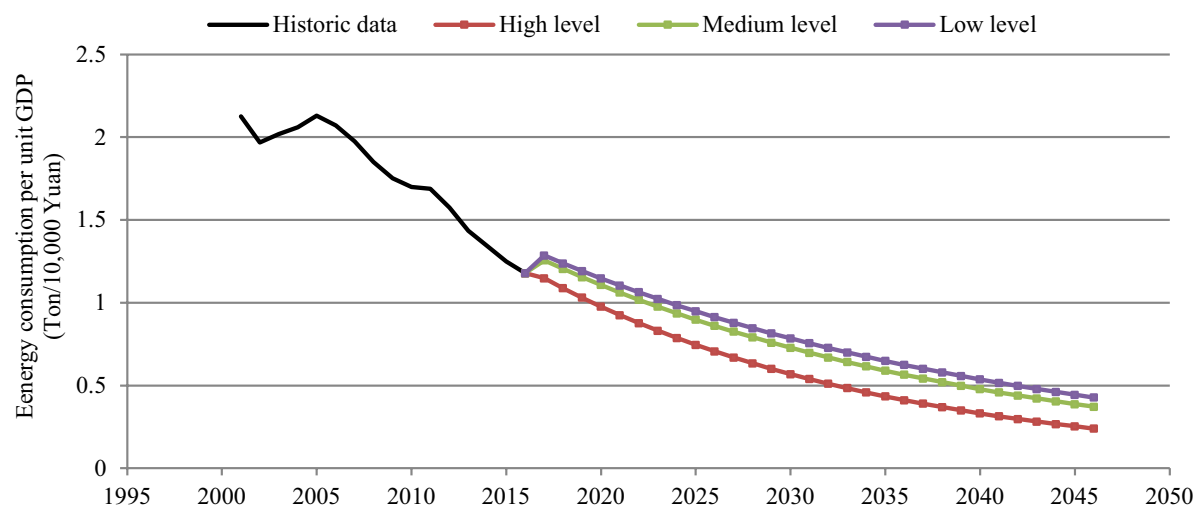

Fig. 5 Change trends in EI

if GDP grows at a high rate $\left(r_{1}=0.05 \%\right)$, China, under $\mathrm{S} 1$, will reach its emission peak in 2044 with $15.58 \mathrm{Gt}$, which is nearly $25 \%$ more than 2016. If GDP grows at a modest rate $\left(r_{1}=0.1 \%\right)$, emission peaks will appear by the end of 2043 in S4 and S5. In S4, GDP grows at a moderate rate; EI decreases by $51.7 \%$, and CI declines by $2.7 \%$. China will peak in 2030 with $14.11 \mathrm{Gt}$, which is approximately 1.13 times of 2016. Compared with S4, only EI declines at a lower rate in S5, while peak value increased by $39.0 \%$, and peak time is delayed by 13 years. If GDP slowly grows, China will peak before 2036 in all three scenarios, and the corresponding peak value ranges from 13.65 to $19.06 \mathrm{Gt}$. However, China is unable to attain its peak before 2045 as long as its GDP growth rate remains unchanged at $6.5 \%$.

The analysis has demonstrated that it would be laborious for China to fill its international promise of reaching the emission peak before 2030, much less maintain the maximum carbon emissions within $12 \mathrm{Gt}$ to better help the world achieve the $2{ }^{\circ} \mathrm{C}$ target. When GDP grows at a low rate, and EI and CI declines faster than the corresponding rate in $\mathrm{S} 7$, this will make it possible to peak before 2030 and limit carbon emissions to less than 12Gt. However, the low GDP growth is not conducive to improving people's living standards and will set obstacles for China's entry into the "high -income" group. Additionally, the rapid reduction of EI and CI will put considerable pressure on the improvement of the energy structure and emission technology. Seeking help from market mechanisms appears to have been realized.

\subsubsection{Estimations of energy MP and carbon marginal abatement cost}

Model (3) and Model (4) are used to estimate the energy right-MP and left-MP, respectively, from 2001 to 2016; the results are shown in Table 5. Right-MP showed a fluctuating upward trend, increasing from 201 yuan/ton in 2001 to 1224 yuan/ton in 2016. A similar change trend is shown in left-MP, which increased from 1654 yuan/ton in 2001 to 6668 yuan/ton. The increase of MP reflects the improvement of productivity over time, and the comparatively higher left-MP indicates that the economic losses caused by reducing one unit energy input is greater than the economic benefits caused by increasing one unit energy input. Based on the right-MP and left-MP, the corresponding right carbon marginal abatement cost (MAC) and left MAC from 2001 to 2016 are measured through dividing MP by CI, and the results are also 


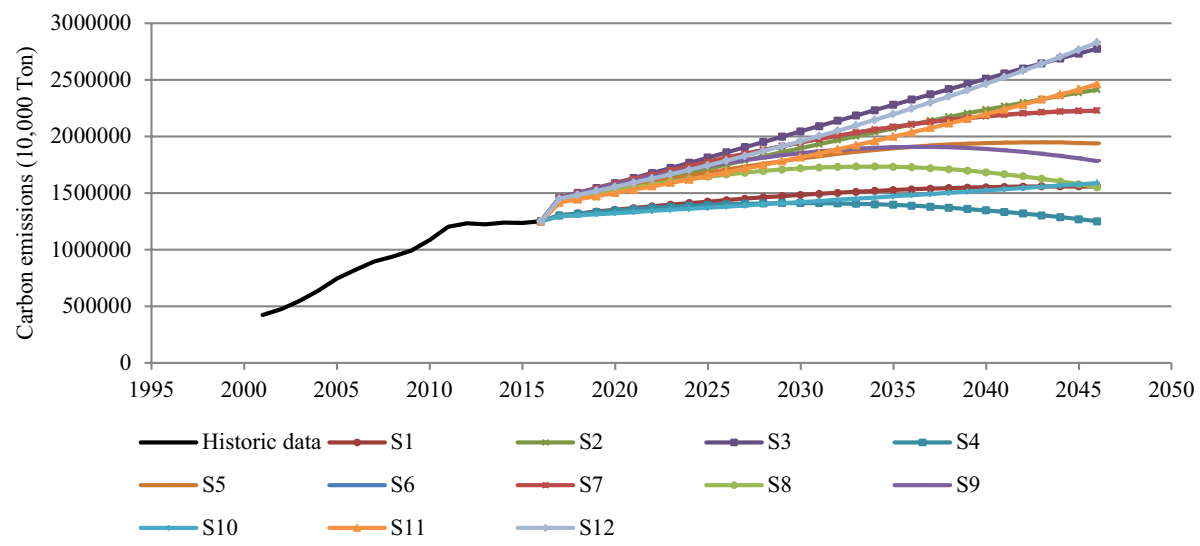

Fig. 6 Change trends in carbon emissions

shown in Table 5. The average MAC ranges from 390 yuan/ton to 1625 yuan/ton, which is lower than the average transportation sectors' and industrial sectors' MAC (Zhou et al. 2015; Wang and He 2017; Xiao et al. 2017) and similar to the provincial level results reported by existing studies (range from 475.3 yuan/ton to 2020 yuan/ton) (Wang et al. 2011, 2018; Wang and Wei 2014; Du et al. 2015; Yang et al. 2018; Wu et al. 2019). Hence, the result obtained in this study is reasonable.

\subsubsection{The impact of carbon ETS on carbon emissions}

Model (15) is employed to evaluate the impact of carbon ETS on carbon emissions given that the GDP cannot be damaged, and Table 6 first reports the energy reduction percentage from implementing nationwide carbon ETS. The second and third columns are the value of energy reduction and energy related emission reduction, respectively. The last column shows the total trading volume of carbon permits in carbon trading markets.

The percentage of energy reduction from carbon ETS ranges from $3.5 \%$ to $13.4 \%$ from 2001-2016, which indicates that approximately $0.969 \mathrm{Gt}$ coal equivalent energy is overused every year over the past 16 years due to the inefficiency of resource allocation, resulting in an additional nearly $1.94 \mathrm{Gt}$ of carbon dioxide emissions per year. Additionally, both energy reduction and emission reduction show an upward trend, which reveals regulatory rigidity on carbon ETS will result in more energy waste and unnecessary carbon dioxide emissions in the future. Thus, implementing carbon ETS as soon as possible is conducive to promoting China's environmental commitments and targets.

In terms of emission trading volume, the annual average value is $0.320 \mathrm{Gt}$, representing approximately $4.3 \%$ of the total average carbon emissions indicating that the carbon trading market is not currently sufficiently vigorous. However, the trading volume increased from $0.0766 \mathrm{Gt}$ in 2001 to $0.495 \mathrm{Gt}$ in 2016 in fluctuation, an increase of approximately 6.46 times reflecting that the activity of the trading market will be improved over time. The lack of vitality in the current market is mainly caused by overallocation of carbon emission permits. However, with the increase of MAC, carbon 


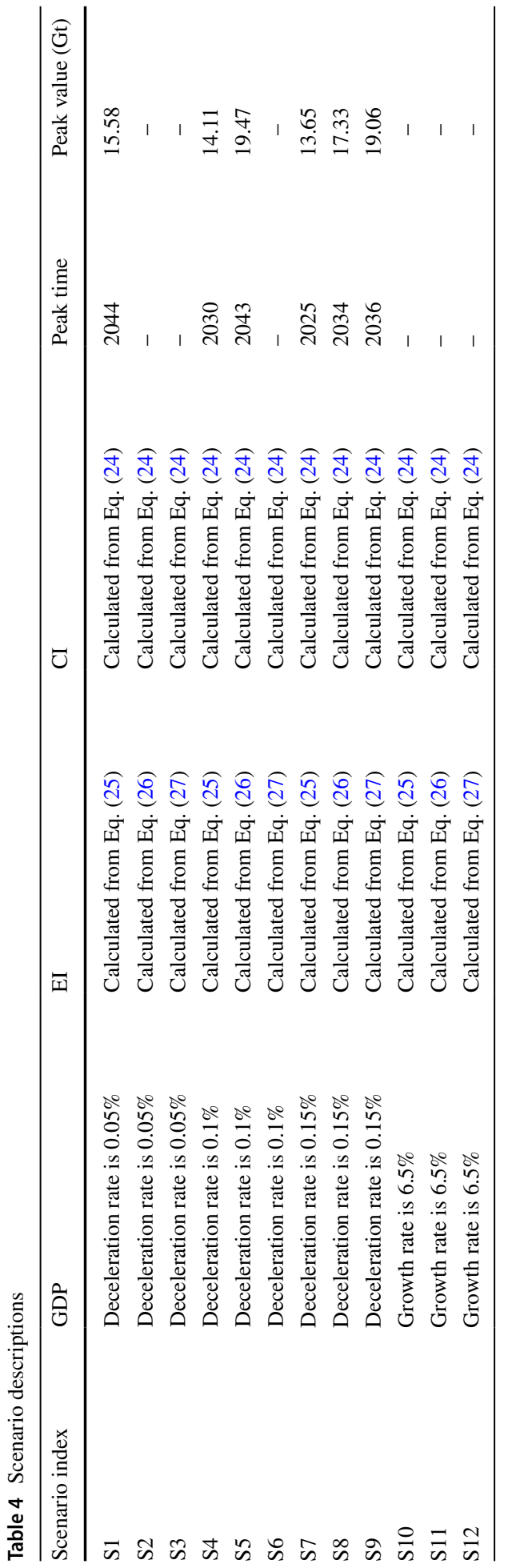


Table 5 Estimations of average energy MP and carbon marginal abatement cost

\begin{tabular}{lllll}
\hline & $\begin{array}{l}\text { Right-MP } \\
(10,000 \text { yuan/ ton })\end{array}$ & $\begin{array}{l}\text { Left-MP } \\
(10,000 \text { yuan/ ton })\end{array}$ & $\begin{array}{l}\text { Right MAC } \\
(10,000 \text { yuan/ ton })\end{array}$ & $\begin{array}{l}\text { Left MAC } \\
(10,000 \text { yuan/ ton })\end{array}$ \\
\hline 2001 & 0.0201 & 0.1645 & 0.0100 & 0.0816 \\
2002 & 0.0349 & 0.1690 & 0.0173 & 0.0839 \\
2003 & 0.0478 & 0.1780 & 0.0237 & 0.0883 \\
2004 & 0.0592 & 0.1848 & 0.0294 & 0.0917 \\
2005 & 0.0671 & 0.1867 & 0.0332 & 0.0924 \\
2006 & 0.0786 & 0.2462 & 0.0390 & 0.1220 \\
2007 & 0.0835 & 0.2421 & 0.0414 & 0.1202 \\
2008 & 0.0901 & 0.3556 & 0.0448 & 0.1768 \\
2009 & 0.0959 & 0.3385 & 0.0477 & 0.1685 \\
2010 & 0.0944 & 0.3116 & 0.0471 & 0.1552 \\
2011 & 0.0706 & 0.3173 & 0.0353 & 0.1586 \\
2012 & 0.0958 & 0.4106 & 0.0480 & 0.2056 \\
2013 & 0.0808 & 0.4642 & 0.0406 & 0.2330 \\
2014 & 0.0777 & 0.4684 & 0.0391 & 0.2356 \\
2015 & 0.1310 & 0.4963 & 0.0660 & 0.2502 \\
2016 & 0.1224 & 0.6668 & 0.0618 & 0.3366 \\
Average & 0.0781 & 0.3250 & 0.0390 & 0.1625 \\
\hline
\end{tabular}

permits, as a kind of production resource, will become increasingly precious; thus, the demand of carbon permits will increase (According to our calculation, the number of provinces demanding carbon emission permits increased from 21 during the 11th FiveYear Plan period to 23 during the 12th Five-Year Plan period and 25 during the 13th Five-Year Plan period.).

Furthermore, to investigate the geographical distribution of demanders and suppliers for carbon emission permits, 29 Chinese provinces are further subdivided into eight economic areas: (1) Northeast area includes Liaoning, Jilin and Heilongjiang. (2) Northern Coastal area contains Beijing, Tianjin, Hebei and Shandong. (3) Eastern Coastal area covers Shanghai, Jiangsu and Zhejiang. (4) Southern Coastal area comprises Fujian, Guangdong and Hainan. (5) Middle Yellow River area consists of Shanxi, Shananxi, Henan and Inner Mongolia. (6) Middle Yangtze River area embraces Hubei, Hunan, Jiangxi and Anhui. (7) Southwest area is comprised by Yunnan, Sichuan, Guangxi and Guizhou. (8) Gansu, Qinghai, Ningxia and Xinjiang are included in Northwest area. The results are shown in Fig. 7.

In Fig. 7, suppliers of carbon emission permits congregate in Northeast China and North China. This finding is mainly because the iron and steel industries, metallurgical industry, and manufacturing were the mainstay industries of these areas in past decades; however, with the transformation and transfer of these polluting industries, carbon emissions in these areas have declined. Thus, these areas have surplus carbon emission rights to supply. In contrast, with the "Rise of central China" proposed, Middle Yangtze River area and part of the Southwest area vigorously develops secondary and tertiary industries (such as equipment manufacturing, pharmaceutical manufacturing, energy exploitation and related deep 
Table 6 The impact of carbon ETS on energy input and carbon emissions

\begin{tabular}{lcllc}
\hline & $\begin{array}{l}\text { Energy reduction } \\
\text { percentage }\end{array}$ & $\begin{array}{l}\text { Energy reduction } \\
\left(10^{\wedge} 4 \text { Ton }\right)\end{array}$ & $\begin{array}{l}\text { Emission reduction } \\
\left(10^{\wedge} 4 \text { Ton }\right)\end{array}$ & $\begin{array}{l}\text { Emission } \\
\text { trading } \\
\text { volume } \\
\left(10^{\wedge} 4 \text { Ton }\right)\end{array}$ \\
\hline 2001 & $3.50 \%$ & $14,767.21$ & $29,750.33$ & $7,658.62$ \\
2002 & $13.10 \%$ & $62,200.26$ & $125,256.75$ & $19,393.21$ \\
2003 & $11.30 \%$ & $61,893.29$ & $124,735.09$ & $31,564.13$ \\
2004 & $11.70 \%$ & $74,383.97$ & $149,980.74$ & $23,770.05$ \\
2005 & $12.90 \%$ & $96,077.71$ & $194,137.43$ & $29,981.53$ \\
2006 & $12.50 \%$ & $102,605.70$ & $207,038.06$ & $33,649.72$ \\
2007 & $13.40 \%$ & $119,997.69$ & $241,717.22$ & $33,335.16$ \\
2008 & $9.60 \%$ & $90,040.45$ & $181,092.55$ & $33,335.16$ \\
2009 & $9.90 \%$ & $98,022.19$ & $196,905.55$ & $29,801.57$ \\
2010 & $9.40 \%$ & $101,957.93$ & $204,653.22$ & $31,998.53$ \\
2011 & $9.80 \%$ & $117,717.99$ & $235,564.24$ & $41,295.03$ \\
2012 & $8.30 \%$ & $102,228.12$ & $204,206.65$ & $39,595.18$ \\
2013 & $11.80 \%$ & $144,485.69$ & $287,852.26$ & $46,340.52$ \\
2014 & $7.40 \%$ & $91,563.70$ & $182,050.82$ & $35,997.98$ \\
2015 & $11.10 \%$ & $137,273.95$ & $272,293.04$ & $24,128.37$ \\
2016 & $10.80 \%$ & $135,016.93$ & $267,479.94$ & $49,536.81$ \\
Average & $10.41 \%$ & $96,889.55$ & $194,044.62$ & $31,961.35$ \\
\hline
\end{tabular}

processing), resulting in the need for a large number of emissions permits; this represents $43.2 \%$ of the total demand. The demand of Eastern Coastal area and Southern Coastal area represents that approximately $46.4 \%$ of the total demand is due to the high carbon abatement cost in these two areas.

\subsubsection{The trajectory of carbon reduction from carbon ETS}

As noted in Sect. 2.2, three means can be used to predict the carbon reduction amount caused by carbon ETS. The first one is predicting the change trend of energy reduction percentage, and the carbon reduction amount is further expressed as the product of $\mathrm{CI}_{t},\left(1-\theta_{t}\right)$ and $\sum_{r=1}^{n} e_{\mathrm{rt}}$. However, it is clear from Table 6 that the trajectory of energy reduction percentage fluctuates excessively resulting in the prediction of energy reduction percentage lacks statistical significance.

The second method directly forecasts the function relationship between carbon reduction volume and time. From the plot (Fig. 8), carbon reduction volume and time show a strong logarithmic function relationship, and the regression function can be expressed as:

$$
\mathrm{TRCO}_{2 t}=73258 \ln (t-2000)+53610\left(R^{2}=0.7897\right)
$$

The third method is determining the hidden factors that affect the carbon reduction volume significantly; then the trajectory of carbon reduction volume is projected based on the change trends of these factors. From model (15), the production technology, the inputs' 


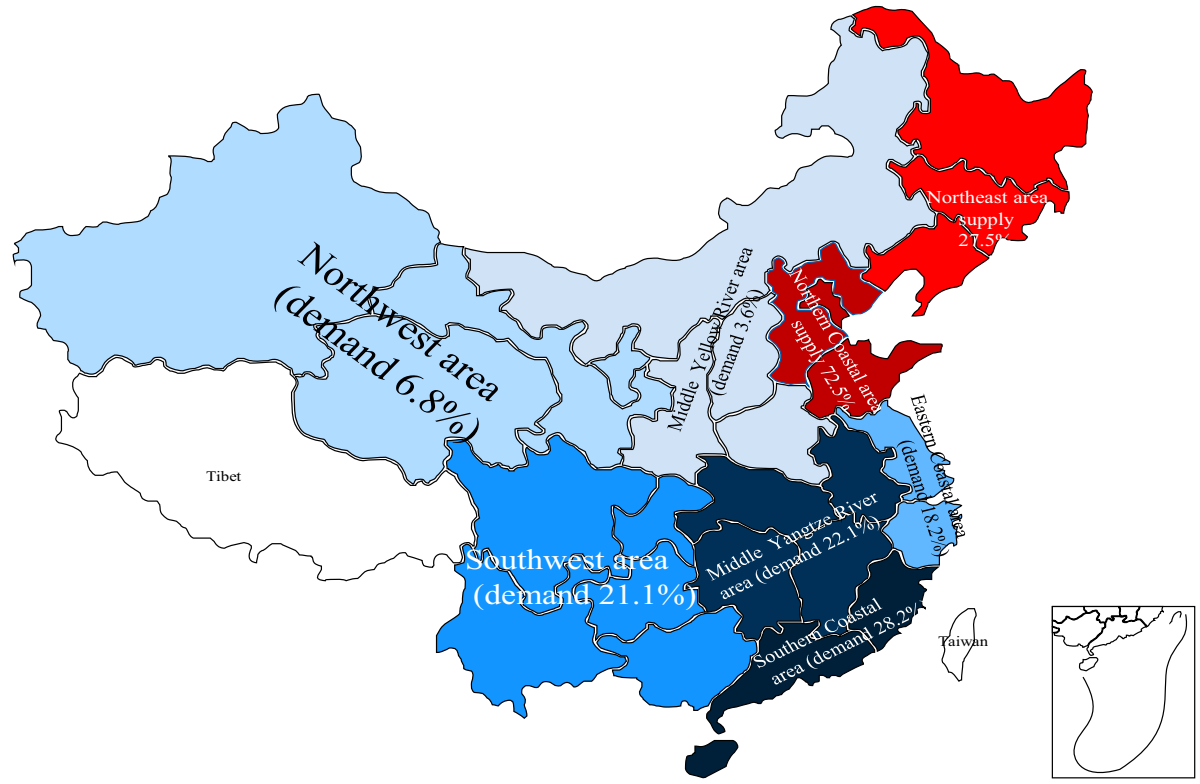

Fig. 7 Geographical distribution of demanders and suppliers for carbon emission permits

level and initial emission permits are the main variables or parameters. Hence, we assumed left MAC, right MAC, total energy input, energy intensity, carbon intensity are hidden factors. Then, the stepwise regression method is employed to identify significant factors among the above factors. The detailed regression results are shown in Tables 7 and 8 . It is shown that the right MAC influences the total emission reduction most significantly, whereas other variables are excluded. The regression model is expressed as:

$$
\mathrm{TRCO}_{2 t}=3.677 * 10^{\wedge} 6 * \mathrm{RMAC}_{t}+50591.58
$$

Furthermore, a good fit between right MAC and logarithm of time can be found from Fig. 9. The future right MAC can be predicted through the following model:

$$
\mathrm{RMAC}_{t}=0.0164 \ln (t-2000)+0.0075\left(R^{2}=0.7869\right)
$$

Hence, the predicted carbon reduction volume under the third method can be expressed as:

$$
\mathrm{TRCO}_{2 t}=60302.8 \ln (t-2000)+78169
$$

Comparing Eq. (27) with Eq. (30), the emission reduction calculated by Eq. (27) is greater than that calculated from Eq. (30). Therefore, in this paper, Eq. (28) is defined as the optimistic estimation model, while Eq. (30) is defined as the conservative estimation model. 


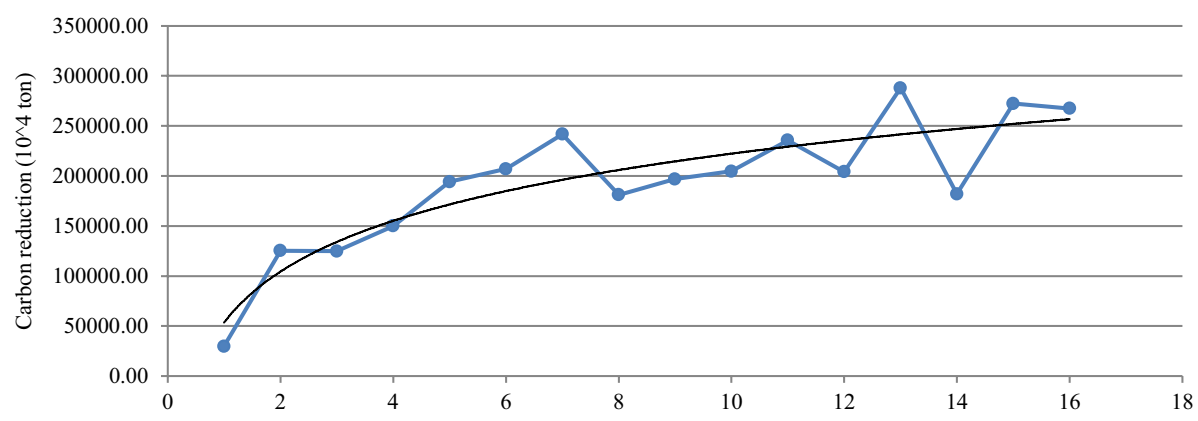

Fig. 8 Change trend in carbon reduction

Table 7 Coefficients of regression model

\begin{tabular}{lllllll}
\hline Model & \multicolumn{2}{l}{$\begin{array}{l}\text { Unstandardized Coef- } \\
\text { ficients }\end{array}$} & & $\begin{array}{l}\text { Standardized } \\
\text { Coefficients }\end{array}$ & Sig \\
\cline { 2 - 3 } & $B$ & SE & Beta & & \\
\hline (Constant) & $50,591.581$ & $27,891.886$ & & 1.814 & .091 \\
Right MAC & $3.677 \mathrm{E} 6$ & $672,125.093$ & .825 & 5.471 & .000 \\
\hline
\end{tabular}

Dependent Variable: Carbon reduction

\subsubsection{Accelerating effect estimation}

Equation (18) is utilized to measure the accelerating effect of carbon ETS on emission peak, and Table 9 reports the detailed results. The fourth and fifth columns show the peak times and peak values with respect to 12 scenarios under an optimistic estimation of carbon ETS. The sixth and seventh columns are peak times and peak values under conservative estimation. Additionally, the last two columns calculate the peak time advances and peak reductions from carbon ETS. From Table 9, the number of scenarios in which Chinese carbon emission peaks occurs before 2030 under carbon ETS remains unchanged at two. However, an evident accelerating effect of carbon ETS can be found; specifically, carbon ETS will be likely to advance the peak time by $1-2$ years and reduce the peak value by 2.71-3 Gt; this pulls China's peak value below the maximum level (12Gt) set by national and international scholars. Among the scenarios in which China can reach its peak around 2030 (S4, S7, S8 and S9), S4 has less concussive impact on GDP than S7, S8 and S9, while it involves greater pressure for improving emission efficiency than S8 and S9. However, when the situation in which the suggested maximum peak value is no more than $12 \mathrm{Gt}$ is considered, $\mathrm{S} 4$ is the most feasible scenario. 
Table 8 Excluded Variables

\begin{tabular}{lccccc}
\hline Model & Beta In & $\mathrm{t}$ & Sig & Partial Correlation & $\begin{array}{l}\text { Col- } \\
\text { linearity } \\
\text { Statistics } \\
\text { Tolerance }\end{array}$ \\
\hline Left MAC & $.066^{\mathrm{a}}$ & .250 & .807 & .069 & .347 \\
Energy input & $.447^{\mathrm{a}}$ & 1.773 & .100 & .441 & .311 \\
Carbon intensity & $-.067^{\mathrm{a}}$ & -.317 & .756 & -.088 & .542 \\
Energy intensity & $-.092^{\mathrm{a}}$ & -.392 & .702 & -.108 & .440 \\
\hline
\end{tabular}

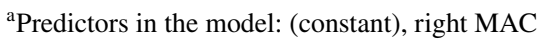

${ }^{\mathrm{b}}$ Dependent variable: carbon reduction

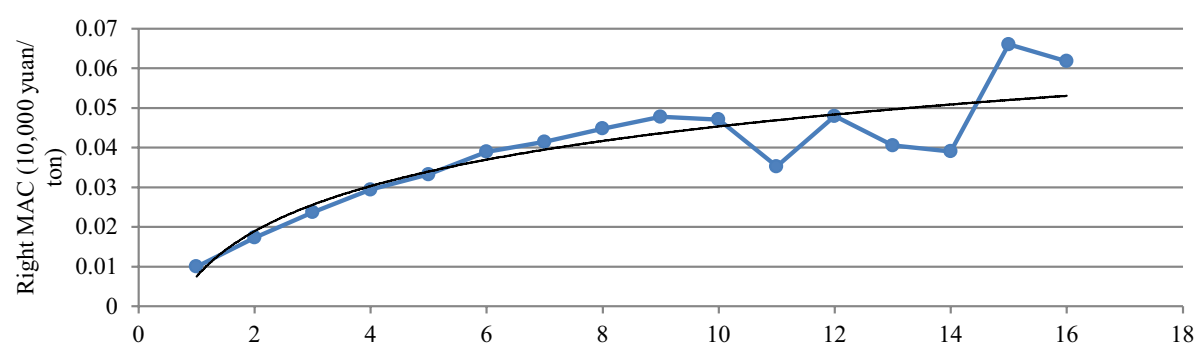

Fig. 9 Change trend in right MAC

\section{Conclusions and Policy Implications}

To prevent "dangerous anthropogenic interference" in the climate system, nearly 200 countries have achieved the consensus that the maximum limitation for temperature rise in this century is $2{ }^{\circ} \mathrm{C}$. As the global largest $\mathrm{CO}_{2}$ emitter, China's commitment on peaking its emissions before 2030 plays an indispensable role in achieving the $2{ }^{\circ} \mathrm{C}$ target. However, through scenario analysis, we found that it would be difficult for China to fulfill its international promise unless, on the one hand, the economic growth slows, and the annual deceleration rate is not less than $0.1 \%$, on the other hand, the energy intensity needs to be reduced at a high rate, and the EI by 2030 should be reduced by nearly $73.3 \%$ compared with the level in 2005. Even if China can reach its peak before 2030 through slowing the economic growth and reducing $\mathrm{EI}$ at a high rate, the peak value is higher than the expected maximum value (i.e., $12 \mathrm{Gt}$ ).

Fortunately, the Chinese government planned to establish a nationwide carbon trading market for entire industries around 2020, and the marked accelerating effect of carbon ETS on carbon peak can be proved through our newly proposed model. Specifically, the peak time under carbon ETS is advanced one to two years, and the peak values in 2024-2028 range from $10.77-10.94 \mathrm{Gt}$ and $11.11-11.29 \mathrm{Gt}$, respectively, with a $2.71-3 \mathrm{Gt}$ reduction in peak value.

Although carbon ETS has an accelerating effect on carbon peak, specific severe problems are also found through this study. First, the average right MAC and left MAC estimated in this paper are 390-1625 yuan/ton, respectively, which are higher than the price 


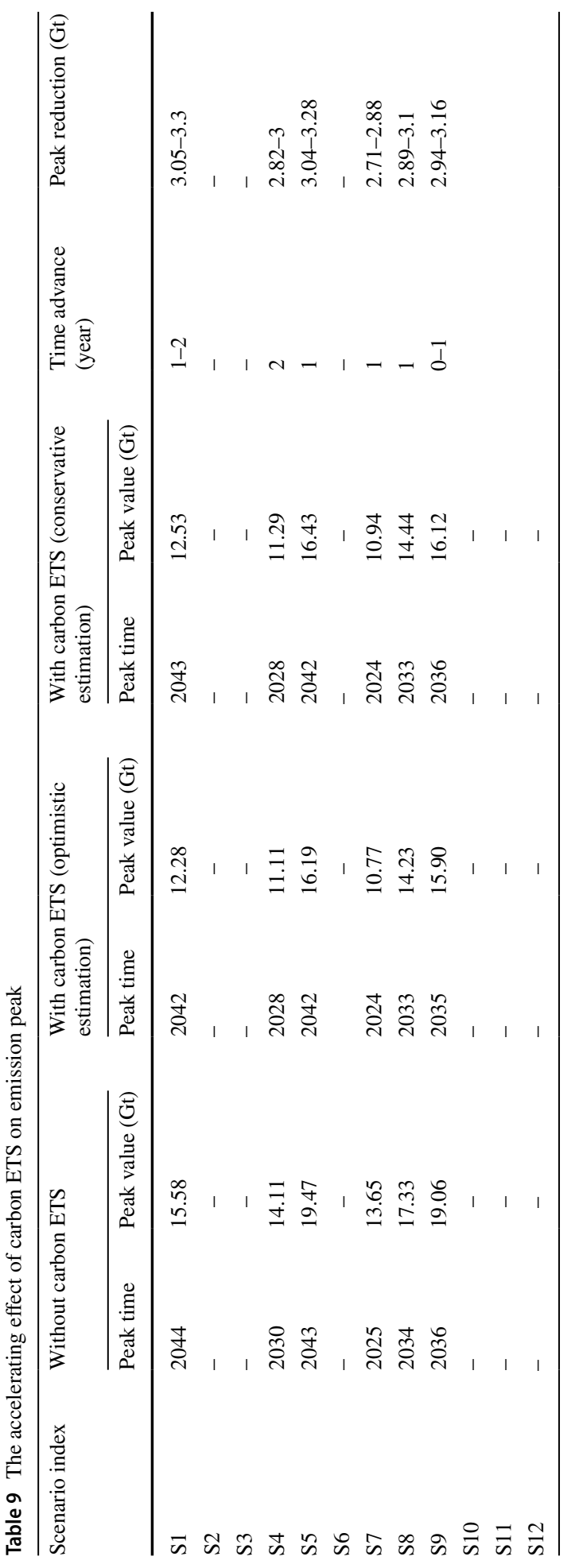


used in China's carbon trading pilot market (approximate 30-50 yuan/ton). The huge gap between MAC and the current carbon trading price demonstrates that the carbon price set in the current carbon market is overly conservative, and price distortion may occur in China's carbon trading pilot market. Second, the annual average carbon trading volume is $0.320 \mathrm{Gt}$ representing only approximately $4.3 \%$ of the total average carbon emissions, indicating that the carbon trading market is not sufficiently vigorous. Additionally, the supply province for carbon emission permits decreased from 8 during the 11th Five-Year Plan period to 6 during the 12th Five-Year Plan period and to 4 during the 13th Five-Year Plan period, which results reveal that China's carbon trading market is likely to fail to achieve a balance between supply and demand, and supply shortages are likely to occur.

Based on the results obtained from this paper, several policy implications are provided regarding the means by which China can more smoothly peak its carbon emissions before 2030 and implement national carbon ETS.

(1) First, the peak target requires China to develop its GDP with a low growth rate, which is not conducive to improving people's living standards and will create obstacles for China's entry into the "high-income" group; hence, enhancing people's sense of access to offset the impact of an economic slowdown on people's lives is the prior problem that needs to be solved.

(2) Second, it is necessary to accelerate the adjustment of the Chinese energy structure, promote the use of clean energy such as nuclear, wind and photovoltaic energy, and vigorously support the development of the tertiary industry. Thus, on the one hand, China can reduce its energy intensity effectively to reach the carbon emissions peak faster; on the other hand, the dependence on emission permits can also be alleviated to prevent the shortage of carbon market supply.

(3) Third, it is of great importance to take effective measures to stimulate the vitality of the Chinese carbon trading market. For example, the carbon trading price should be carefully designed, ${ }^{1}$ and the Chinese government should slowly raise the carbon trading price to modify the fact that market pricing is inefficient. Furthermore, the excessive issuance of carbon emission permits is also one of the reasons for the inadequate vitality of the carbon trading market. Therefore, the Chinese government should reduce its carbon emission permits issuance, and the allocation of carbon emission rights should gradually shift from free issuance to an auction-based mode.

(4) Finally, technological progress plays a critical role in reducing carbon emissions. Government, at all levels, can actively build platforms for scientific and technological innovation, increase R\&D investment and enact other initiatives to promote the technological innovation on carbon emissions. It should be noted that technological progress may cause an increase in carbon emissions rather than a decrease (this phenomenon is called the rebound effect); hence, while developing science and technology, the additional carbon dioxide emissions caused by the rebound effect should be controlled.

Although our method takes the unsmooth characteristic of the DEA production frontier into account, there are still some defects, which also exist in the DEA-based methods

\footnotetext{
1 In a perfect market, price is a kind of market signal, which is mainly determined by many market factors, such as fuel price, macroeconomic, weather and other factors. It cannot be adjusted by the government at will. However, China's carbon trading market is still in its infancy, and its price is largely affected by non-market factors, such as government regulation. Hence, we suggested that China should carefully set its carbon trading price. The price set by the government is more of a guide price rather than a precise trading price. And the precise trading price can be determined by other market factors on the basis of guide price.
} 
mentioned in the literature review, can be further filled. For example, the carbon emissions trading process is treated as a black box problem and discussions on some detailed issues, such as the setting of carbon trading price and the choice of carbon permits allocation mode, are ignored. Hence, how to open the black box of carbon trading in DEA-based methods is worthy of further study. Moreover, our models do not take into account non policy events, such as the outbreak of covid-19, which may lead to bias in our estimates. How to integrate the impact of these events into models and improve the robustness of models is one of the hot research directions in the future. Finally, we only considered a simple situation, that is, a province is either the seller or the buyer, which may cause biases if the differentiated pricing strategies are adopted. Hence, it is also worthwhile investigating the trading strategies when a province can be both a seller and a buyer.

Acknowledgements Thanks are due to Yuanqiao Li for assistance with the writing and valuable discussion. This work is supported by the National Natural Science Foundation of China (Grant 71904084), Postdoctoral Science Foundation of China (Grant 2020TQ0145), the Natural Science Foundation for Jiangsu Province, China (Grant BK20190427), the Social Science Foundation of Jiangsu Province, China (Grant 19GLC017), and the Fundamental Research Funds for the Central Universities, China (Grant NR2019003), and the Innovation and Entrepreneurship Foundation for Doctor of Jiangsu Province, China.

\section{Compliance with ethical standards}

Conflict of interest The authors declare that they have no conflict of interest.

\section{References}

den Elzen M, Fekete H, Höhne N et al (2016) Greenhouse gas emissions from current and enhanced policies of China until 2030: can emissions peak before 2030? Energy Policy 89:224-236. https://doi. org/10.1016/j.enpol.2015.11.030

Du L, Hanley A, Wei C (2015) Estimating the marginal abatement cost curve of $\mathrm{Co}_{2}$ emissions in China: provincial panel data analysis. Energy Econ 48:217-229. https://doi.org/10.1016/j.eneco.2015.01.007

Färe R, Grosskopf S, Pasurka CA (2013) Tradable permits and unrealized gains from trade. Energy Econ 40:416-424. https://doi.org/10.1016/j.eneco.2013.07.015

Färe R, Grosskopf S, Pasurka CA (2014) Potential gains from trading bad outputs: the case of U.S. electric power plants. Resour Energy Econ 36:99-112. https://doi.org/10.1016/j.reseneeco.2013.11.004

Hübler M, Voigt S, Löschel A (2014) Designing an emissions trading scheme for China-an up-to-date climate policy assessment. Energy Policy 75:57-72. https://doi.org/10.1016/j.enpol.2014.02.019

Kawase R, Matsuoka Y, Fujino J (2006) Decomposition analysis of $\mathrm{CO}_{2}$ emission in long-term climate stabilization scenarios. Energy Policy 34:2113-2122. https://doi.org/10.1016/j.enpol.2005.02.005

Kaya Y, Yokobori K (1997) Environment, energy, and economy: strategies for sustainability. United Nation University Press, Tokyo

Khanna NZ, Zhou N, Fridley D, Ke J (2016) Quantifying the potential impacts of China's power-sector policies on coal input and $\mathrm{CO}_{2}$ emissions through 2050: a bottom-up perspective. Util Policy 41:128-138. https://doi.org/10.1016/j.jup.2016.07.001 
Lee C, Johnson AL (2014) Proactive data envelopment analysis: effective production and capacity expansion in stochastic environments. Eur J Oper Res 232:537-548. https://doi.org/10.1016/j. ejor.2013.07.043

Li W, Jia Z (2016) The impact of emission trading scheme and the ratio of free quota: a dynamic recursive CGE model in China. Appl Energy 174:1-14. https://doi.org/10.1016/j.apenergy.2016.04.086

Li G, Yang J, Chen D, Hu S (2017) Impacts of the coming emission trading scheme on China's coal-tomaterials industry in 2020. Appl Energy 195:837-849. https://doi.org/10.1016/j.apenergy.2017.03.115

Li M, Mi Z, Coffman DM, Wei YM (2018) Assessing the policy impacts on non-ferrous metals industry's $\mathrm{CO}_{2}$ reduction: evidence from China. J Clean Prod 192:252-261. https://doi.org/10.1016/j.jclep ro.2018.05.015

Liu L, Sun X, Chen C, Zhao E (2016) How will auctioning impact on the carbon emission abatement cost of electric power generation sector in China? Appl Energy 168:594-609. https://doi.org/10.1016/j.apene rgy.2016.01.055

Liu Y, Tan XJ, Yu Y, Qi SZ (2017) Assessment of impacts of Hubei Pilot emission trading schemes in China-a CGE-analysis using term $\mathrm{CO}_{2}$ model. Appl Energy 189:762-769. https://doi.org/10.1016/j. apenergy.2016.05.085

Meng M, Jing K, Mander S (2017) Scenario analysis of $\mathrm{CO}_{2}$ emissions from China's electric power industry. J Clean Prod 142:3101-3108. https://doi.org/10.1016/j.jclepro.2016.10.157

Mi Z, Wei YM, Wang B et al (2017) Socioeconomic impact assessment of China's $\mathrm{CO}_{2} \mathrm{cx}$ emissions peak prior to 2030. J Clean Prod 142:2227-2236. https://doi.org/10.1016/j.jclepro.2016.11.055

Niu S, Liu Y, Ding Y, Qu W (2016) China's energy systems transformation and emissions peak. Renew Sustain Energy Rev 58:782-795. https://doi.org/10.1016/j.rser.2015.12.274

Podinovski VV, Førsund FR (2010) Differential characteristics of efficient frontiers in data envelopment analysis. Oper Res 58:1743-1754. https://doi.org/10.1287/opre.1090.0794

Rout UK, Voß A, Singh A et al (2011) Energy and emissions forecast of China over a long-time horizon. Energy 36:1-11. https://doi.org/10.1016/j.energy.2010.10.050

Song X, Lu Y, Shen L, Shi X (2018) Will China's building sector participate in emission trading system? Insights from modelling an owner's optimal carbon reduction strategies. Energy Policy 118:232-244. https://doi.org/10.1016/j.enpol.2018.03.075

Tang L, Wu J, Yu L, Bao Q (2015) Carbon emissions trading scheme exploration in China: a multi-agentbased model. Energy Policy 81:152-169. https://doi.org/10.1016/j.enpol.2015.02.032

Tang B, Li R, Yu B et al (2018) How to peak carbon emissions in China's power sector: a regional perspective. Energy Policy 120:365-381. https://doi.org/10.1016/j.enpol.2018.04.067

Tol RSJ (2013) Targets for global climate policy: an overview. J Econ Dyn Control 37:911-928. https://doi. org/10.1016/j.jedc.2013.01.001

Wang $\mathrm{Z}, \mathrm{He} \mathrm{W}$ (2017) $\mathrm{CO}_{2}$ emissions efficiency and marginal abatement costs of the regional transportation sectors in China. Transp Res Part D Transp Environ 50:83-97. https://doi.org/10.1016/j. trd.2016.10.004

Wang K, Wei YM (2014) China's regional industrial energy efficiency and carbon emissions abatement costs. Appl Energy 130:617-631. https://doi.org/10.1016/j.apenergy.2014.03.010

Wang Q, Cui Q, Zhou D, Wang S (2011) Marginal abatement costs of carbon dioxide in China: a nonparametric analysis. Energy Procedia 5:2316-2320. https://doi.org/10.1016/j.egypro.2011.03.398

Wang P, Dai H, cheng, Ren S yan, et al (2015) Achieving Copenhagen target through carbon emission trading: Economic impacts assessment in Guangdong Province of China. Energy 79:212-227. https://doi. org/10.1016/j.energy.2014.11.009

Wang K, Wei YM, Huang Z (2016a) Potential gains from carbon emissions trading in China: a DEA based estimation on abatement cost savings. Omega 63:48-59. https://doi.org/10.1016/j.omega.2015.09.011

Wang K, Zhang X, Yu X et al (2016b) Emissions trading and abatement cost savings: an estimation of China's thermal power industry. Renew Sustain Energy Rev 65:1005-1017. https://doi.org/10.1016/j. rser.2016.07.051

Wang Y, Wang Q, Hang Y et al (2018) CO2emission abatement cost and its decomposition: a directional distance function approach. J Clean Prod 170:205-215. https://doi.org/10.1016/j.jclepro.2017.09.122

Wu L, Gong Z (2020) Can national carbon emission trading policy effectively recover GDP losses? A new linear programming-based three-step estimation approach. J Clean Prod. https://doi.org/10.1016/j.jclep ro.2020.125052

Wu L, Chen Y, Feylizadeh MR, Liu W (2018) Estimation of China's macro-carbon rebound effect: method of integrating data envelopment analysis production model and sequential Malmquist-Luenberger index. J Clean Prod 198:1431-1442. https://doi.org/10.1016/j.jclepro.2018.07.034 
Wu L, Chen Y, Feylizadeh MR (2019) Study on the estimation, decomposition and application of China's provincial carbon marginal abatement costs. J Clean Prod 207:1007-1022. https://doi.org/10.1016/j. jclepro.2018.10.082

Xiao B, Niu D, Guo X (2017) Marginal abatement cost of CO2 in China based on directional distance function: an industry perspective. Sustainability. 9:138. https://doi.org/10.3390/www.mdpi.com/journ al/energies

Yang L, Li F, Zhang X (2016) Chinese companies' awareness and perceptions of the emissions trading scheme (ETS): evidence from a national survey in China. Energy Policy 98:254-265. https://doi. org/10.1016/j.enpol.2016.08.039

Yang L, Tang K, Wang $\mathrm{Z}$ et al (2018) Regional eco-efficiency and pollutants' marginal abatement costs in China: a parametric approach. J Clean Prod 167:619-629. https://doi.org/10.1016/j.jclep ro.2017.08.205

Yu S, Zheng S, Li X, Li L (2018a) China can peak its energy-related carbon emissions before 2025: evidence from industry restructuring. Energy Econ 73:91-107. https://doi.org/10.1016/j.eneco.2018.05.012

Yu Y, Zhang W, Zhang N (2018b) The potential gains from carbon emissions trading in China's industrial sectors. Comput Econ 52:1175-1194. https://doi.org/10.1007/s10614-017-9724-2

Yuan J, Xu Y, Hu Z et al (2014) Peak energy consumption and $\mathrm{CO}_{2}$ emissions in China. Energy Policy 68:508-523. https://doi.org/10.1016/j.enpol.2014.01.019

Zhang J, Wu G, Zhang J (2004) The estimation of China's provincial capital stock: 1952-2000. Econ Res J 10:35-44

Zhang YJ, Liu Z, Qin CX, De TT (2017) The direct and indirect $\mathrm{CO}_{2}$ rebound effect for private cars in China. Energy Policy 100:149-161. https://doi.org/10.1016/j.enpol.2016.10.010

Zhou X, Fan LW, Zhou P (2015) Marginal $\mathrm{CO}_{2}$ abatement costs: findings from alternative shadow price estimates for Shanghai industrial sectors. Energy Policy 77:109-117. https://doi.org/10.1016/j.enpol .2014 .12 .009

Zhu L, Zhang XB, Li Y et al (2017) Can an emission trading scheme promote the withdrawal of outdated capacity in energy-intensive sectors? A case study on China's iron and steel industry. Energy Econ 63:332-347. https://doi.org/10.1016/j.eneco.2017.02.004

Zhu Q, Li X, Li F, Zhou D (2019) The potential for energy saving and carbon emission reduction in China's regional industrial sectors. Sci Total Environ 716:135009. https://doi.org/10.1016/j.scito tenv.2019.135009

Zhu Q, Li X, Li F et al (2020a) Analyzing the sustainability of China's industrial sectors: a data-driven approach with total energy consumption constraint. Ecol Indic. https://doi.org/10.1016/j.ecoli nd.2020.107235

Zhu Q, Li X, Li F et al (2020b) Energy and environmental efficiency of China's transportation sectors under the constraints of energy consumption and environmental pollutions. Energy Econ 89:104817. https:// doi.org/10.1016/j.eneco.2020.104817

Publisher's Note Springer Nature remains neutral with regard to jurisdictional claims in published maps and institutional affiliations. 